\title{
Defeaters in current epistemology: introduction to the special issue
}

\author{
Luca Moretti \\ University of Aberdeen/MCMP \\ 1.moretti@abdn.ac.uk
}

\author{
Tommaso Piazza \\ University of Pavia \\ tommaso.piazza@unipv.it
}

Suppose you see that a red light is shining at the wall before you, or that the painter tells you that the wall is white. When this happens, your perceptual justification for believing that the wall is red is typically defeated. In the last few years there has been a surge of attention to the topic of defeaters. Symptoms and consequences of this are, for example, Sudduth (2017)'s entry “Defeaters in Epistemology" of the Internet Encyclopedia of Philosophy, and Grundmann (2011)'s chapter "Defeasibility Theories" of the Routledge Companion to Epistemology (edited by Bernecker and Pritchard). The expression "epistemic defeasibility" refers to a belief's or a proposition's liability to lose, have it downgraded or be prevented from acquiring some positive epistemic status, such asfor instance — being justified, being warranted or being knowledge. An epistemic defeaterpossibly coinciding with an experience, a reason, a belief or a fact—is, broadly speaking, what actualizes this possibility.

The extant literature on epistemic defeaters has mainly been driven by the aims to (1) identify epistemic statuses that constitute the target of epistemic defeat, and (2) understand and classify the "mechanisms" in virtue of which defeaters negatively impact on the epistemic statuses that constitute their targets. Recently, research on defeaters has also been driven by (3) the recognition that a number of important questions in epistemology can be illuminated by inspecting roles played by defeaters, and by the recognition that debates between rival epistemological theories can sometimes be decided by comparing their explanatory power with respect to (different types of) defeaters. 
In relation to issues of type (1), Bergmann (2006)'s distinction between a propositional defeater-namely, a proposition that would negatively impact on a subject $S$ 's current justification, were $S$ to become aware of its truth—and a mental defeater-namely, a mental state of $S$ that actually negatively impacts on $S$ 's current justification — appears to be a stable acquisition. The mere existence of a propositional defeater of $S$ 's justification for believing $P$ hasn't the power to take this justification away from $S$. In spite of this, $S$ 's justification is negatively affected by the mere existence of such a defeater. According Bergmann (2006) and other epistemologists (Chisholm 1964, Lehrer and Paxson 1969, Klein 1976, Swain 1974, De Almeida and Fett 2015), in particular, the mere existence of a propositional defeater has the power to make $S$ 's justification unfit to sustain knowledge. ${ }^{1}$ For these epistemologists, this happens because $S$ 's justification, in order to sustain knowledge, must be resilient to the acquisition of new true beliefs, whereas the existence of a propositional defeater entails that $S$ 's justification is liable to get destroyed upon $S$ 's acquiring a new true belief. The epistemic status that constitutes the target of propositional defeaters - strictly speaking - is hence not justification but knowledge. The existence of a mental defeater, on the other hand, has the power to prevent $S$ 's beliefs from being justified.

Whether there could be justification immune to this kind of defeaters is a question that has also attracted considerable attention. For instance, McDowell (2008, 2010 and 2011) has defended the view that when we are in genuine perceptual contact with reality, there is no possibility that we are deceived, with the consequence that the justification we have for our environmental beliefs is indefeasible. In response, Dennis (2014) contends that McDowell's conclusion doesn't follow from the claim, distinctive of McDowell's (and Pritchard 2012's) epistemological disjunctivism, that in the good case — when we are in genuine contact with reality — our environmental beliefs enjoy a factive epistemic support. According to Dennis, $S$ 's factive epistemic support can be defeated when $S$ receives misleading information about the suitability of the conditions in which $S$ has acquired her beliefs. Recent investigation has also focussed on the question whether the justification attainable

\footnotetext{
${ }^{1}$ We refer to knowledge-that. An important paper that attempts to model defeat of knowledge-how is Carter and Navarro (2017).
} 
for believing statements of certain types - e.g. about one's own sensations, or about simple logical and mathematical facts - could be defeated. Some epistemologists have returned negative answers (cf. Williamson 2007 and Grundmann 2011).

More complex indefeasibility claims have also been scrutinized-e.g. the thesis that certain sources of justification are negatively autonomous in Audi (2002)'s sense; namely, defeasible only by information coming from the same source. Janvid (2008 and 2012) and Thurow (2006) argue that a priori justification can be defeated by empirical considerations. Less recent examples of this view include Casullo (2003). Warenski (2009) has argued for the more moderate claim that the notion of indefeasibility is essential to the concept of a priori justification, but only if the notion of indefeasibility interpreted in a fallibilist way.

A preliminary issue emerging in relation to issues of type (2) pertains to the general characterization of a defeater. Along with the venerable tradition initiated by Pollock (1987), $D$ is a defeater of $E$ 's support for $P$ for $S$ if and only if (i) $E$ is a reason to believe $P$ for $S$ and (ii) $E \& D$ is not a reason to believe $P$ for $S$. As Chandler (2013) has shown, however, Pollock's characterization can be disputed on the ground that it is insensitive to what can be called justifying defeaters. A justifying defeater $J D$ of $E$ 's support for $P$ for $S$ does two things: it prevents $E$ from being a reason to believe $P$ for $S$ but, at the same time, it supplies $S$ with a new reason to believe $P$. So $J D$ is a defeater for $S$, but it does not fulfil the clause (ii) of Pollock's bi-conditional, as $E \& J D$ still is a reason for $S$ to believe $P$.

As far as the "mechanics" of defeat is concerned, Pollock (1974)'s early distinction between rebutting (aka overriding), and undercutting (aka undermining) defeaters still occupies centre stage. A rebutting defeater for a belief that $P$ of $S$ is, roughly, a reason of $S$ for believing the negation of $P$ or for believing some proposition $Q$ incompatible with $P$. Whereas an undercutting defeater for a belief that $P$ of $S$ is, roughly, a reason of $S$ that attacks the connection between $S$ 's ground for believing $P$ and $P$ (as we'll see shortly, Pollock has long favoured a counterfactual reading of the latter condition). Pollock's distinction is mostly regarded as exclusive, but this according to Pryor 
(2013) can be disputed on the basis of the following considerations. Suppose $S$ 's justification for believing $P$ from evidence $E$ is rebutted, as $S$ acquires new evidence $E^{*}$ that more strongly supports a second proposition $Q$, which is incompatible with $P$. When this happens, $S$ is left with the question of why $P$ is false even if $E$ is true. Pryor's suggestion is that the best answer available to $S$ is that, in the present context, $E$ is not a reliable indicator of the truth of $P$. Hence $E^{*}$ supplies $S$ with some evidence against $E$ 's reliability and in doing this it also acts as an undercutting defeater of $S$ 's justification from $E$ for believing $P$.

Many epistemologists concentrate on the task of further clarifying Pollock's notion of undermining defeat, and of better elucidating its relation to the notion of rebutting defeat (e.g. Casullo 2003, Rotondo 2013, Sturgeon 2014 and Melis 2014). On Pollock's characterization of the distinction, the rebutting and undercutting defeaters of the justification of $S$ from $E$ for $P$ both exert their negative effect by supplying $S$ with reasons for believing further propositions. As said, in particular, rebutting defeaters exert their negative effect by supplying $S$ with reasons for believing the negation of $P$ or a proposition incompatible with $P$. Undercutting defeaters, on the other hand, exert their negative effect by attacking the connection between $S$ 's evidence $E$ and $P$. In particular, for Pollock this means that undercutting defeaters give $S$ reasons for believing that it is not the case that $E$ wouldn't have been true unless $P$ had been true.

This characterization has come under attack in recent years. Sturgeon (2014) and Melis (2014) argue that undercutting and rebutting defeaters in fact exemplify two essentially different kinds of defeat. Sturgeon, in particular, contends that while rebutting defeaters produce their effect all by themselves (by providing $S$ with reasons to believe an incompatible proposition), undercutting defeaters work in tandem with higher-order commitments pertaining to the epistemic basis of $S$ 's first-order beliefs. In more detail, according to Sturgeon $S$ 's belief that a source $S R$ is untrustworthy regarding whether or not $P$ is true undercuts $S$ 's justification for her belief that $P$ just in case $S$ believes that $P$ is based on source $S R$. This principle explains, for Sturgeon, the intuition that $S$ 's mere belief that $S R$ is an untrustworthy source is unable to undercut $S$ 's justification coming from 
$S R$ in situations in which $S$ doesn't also believe that $S R$ is the source of this justification. (For a critical assessment of Sturgeon's view, see Casullo's article in this special issue).

Some epistemologists have explored whether formal epistemology could model the phenomenon of defeat. Weisberg (2009 and 2015) maintains that both Jeffrey conditionalization, within the Bayesian framework, and Dempster-Shafer conditionalization are at odds with basic features of undermining defeaters because they are in a sense "too rigid". Pryor (2013) contends that Bayesianism cannot model a type of undermining defeat that we should expect to exist if certain views in epistemology_-including one defended in the past by Pryor himself, called dogmatism - were correct.

An important question addressed within the literature of type (2) is whether defeaters of either variety must themselves be true or justified in order to exert their negative impact on $S$ 's justification. Lackey (2008)'s distinction between doxastic defeaters and normative defeaters is relevant to this topic. Doxastic defeaters are beliefs of $S$, not necessarily true or justified, that speak in favour of the claim that $S$ 's belief that $P$ is false or is based on an unreliable source. Normative defeaters are reasons for entertaining doxastic defeaters.

Another trend in recent epistemology is explaining the defeating power (if any) of higherorder evidence - namely, of evidence that works by inducing doubts that one's first-order beliefs are the output of a flawed process, such as a calculation mistake, an erroneous assessment of one's first-order evidence, or the application of an incorrect epistemic rule (see for instance Christensen 2007a, 2007b, 2007c, 2009 and 2010, Feldman 2009, Kelly 2010, Schechter 2011, and LasonenAarnio 2014). If higher-order evidence has the defeating power which most epistemologists tend to credit it with, it instantiates a fundamentally different kind of defeat. For, unlike rebutting and undercutting defeaters, it doesn't simply destroy one's justification for believing a proposition. It also shows that this justification, the corresponding belief being the product of cognitive malfunction, has never been in place to start with. A more specific question arising in connection with the topic of the defeating power of higher-order evidence is whether one's known peer 
disagreement has the power to defeat one's justification. Standard answers to this question can be used to illustrate the different positions available in response to the general question pertaining to the defeating power of higher-order evidence. These answers divide into two broad categories. Suppose $S$ believes $P$ on the basis of $E$, and that $S^{\prime}$ s epistemic peer $S^{*}$ has access to the same evidence. The non-conciliatory or steadfastist views maintain that upon $S$ coming to know that $S^{*}$ disbelieves $P, S$ should neither lower her confidence that $P$ nor her confidence that $E$ supports $P$ (see Kelly 2005 and Titelbaum 2015). The conciliatory or conformist views maintain, on the other hand, that upon $S$ coming to know that $S^{*}$ disbelieves $P, S$ should both lower her confidence that $P$ and her confidence that $E$ actually supports $P$ (see for instance Feldman 2005). ${ }^{2}$

As emphasized by Horowitz (2014), both kinds of answers appear to presuppose the general thesis that it is never rational for a subject $S$ to believe $P$ on the basis of $E$ while believing that $E$ doesn't actually support $P$. This general thesis amounts to the claim that epistemic akrasia - the attitude of believing contrary to what one believes one ought epistemically to believe-can never be rational. This thesis has recently come under attack in, among others, Wedgwood (2011), Coates (2012) and Lasonen-Aarnio (2014). These epistemologists insist that epistemic akrasia can be rational at least in certain cases in which $S$ 's first-order evidence $E$ supports $S$ 's belief that $P$ and $S$ has acquired misleading higher-order evidence that $E$ doesn't adequately support $P$. In these circumstances - they contend - it can both be rational for $S$ to believe $P$ on the basis of $E$ and simultaneously believe that $E$ does not adequately support $P$. These akratic views have in turn been criticised by Horowitz (2014) on the ground that they would license intuitively bad reasoning and irrational behaviour.

In relation to issues of type (3), the controversy between conservatives and liberals about the architecture of perceptual justification has considerably fostered the interest for the epistemic role played by defeaters. (This debate is for instance outlined in Moretti and Piazza 2013) According to the conservative — prominently, Wright (2004)—S's experience that $P$ supplies $S$ with

\footnotetext{
2 Papers relevant to this debate are for instance Carey (2011), Cohen (2013), Comesana (2012), Feldman (2009), Kelly
} (2005) and (2010), Matheson (2009) Rotondo (2013), Thune (2010), and Weatherson (2013). 
justification for believing $P$ only if $S$ has independent justification for ruling out any potential defeater. According to the liberal—-for example, Pryor (2000)'s dogmatist— $S$ doesn't need this independent justification. An important form of liberalism hotly discussed nowadays — also in relation to defeaters - is phenomenal conservatism (see Moretti 2015). ${ }^{3}$ It should be clear that the foundationalist thesis that there is non-inferential (or basic) justification crucially presupposes some form of liberalism and a correlated conception of defeat.

An increasingly popular argumentative trend in epistemology is the following: philosophers start with the claim that defeaters (in general, or of a specific variety) exist. They then argue from this premise in favour or against specific accounts of various epistemological notions in light of the observation that these theories (best) explain or fail to explain that defeaters (in general, or of that specific variety) exist. For example, BonJour (1980) has argued that the existence of defeaters can help us settle the dispute between internalism and externalism about justification in favour of the former because externalism cannot accommodate defeaters of a certain type whose existence can hardly be denied. (For critical discussion see Grundmann 2009.) Johnson (2011) argues against proper function theories of epistemic justification from the premise that these theories fail to explain the defeating power of certain experiences. Silins (2014) observes that the conservative conception of the architecture of perceptual justification seems better suited than the liberal one to explain how perceptual justification can be defeated. In the end, however, he offers a general explanation of the defeat of perceptual justification that does not presuppose the conservative view. Pryor (2013) characterizes a general position in epistemology that he dubs credulism (which is a weaker version of his dogmatism) in terms of the commitment descending from it to recognizing the existence of what he calls non-quotidian defeaters. Pryor tackles the criticism of credulism (and dogmatism) according to which Bayesianism cannot model the existence of non-quotidian defeaters and assesses alternatives to the option of abandoning credulism.

\footnotetext{
${ }^{3}$ To forestall possible confusion, the reader should keep it in mind that the expression 'conservatism' is used in very different ways, which not always conform to the dichotomy liberalism/conservatism, in current epistemology and even by the contributors to this special issue.
} 
The articles collected in this special issue of Synthese aim to contribute to the three debates centred on the themes of defeat and justification that we have just described. We have tried to sort out these articles depending on whether they aim to: (1) individuate the target of certain defeaters, (2) clarify in virtue of what mechanisms defeaters negatively impact on their targets, or (3) support a given epistemological view by assessing its ability to explain defeat. (Since some papers neatly pursue just one of these goals but others contribute to more than one, the reader cannot but find our categorisation somewhat unfitting.)

Contributions of type (1)

Carla Bagnoli's article "Defeaters and practical knowledge" endeavours to reconcile the defeasible character of moral obligations with a constructivist account of the source of their authority. Bagnoli opposes what she calls "the radical account of defeasibility" that is offered by Dancy's moral particularism and Koorsgaard's proceduralism. In contrast with such views, Bagnoli defends a "moderate" account of defeasibility compatible with the Kantian thesis that the only source of moral authority is reasoning guided by general moral principles. The constructivist view delineated by Bagnoli, in particular, accommodates some ordinary sources of defeasibility which are best regarded as hinging on the agent's own moral progress.

Adam Carter's "Meta-epistemic defeat" offers an account of what he calls meta-epistemic defeaters. A first-order defeater is any ordinary (rebutting or undermining) defeater. A defeater of this type only downgrades the first order epistemic status of a belief. Typical examples of firstorder epistemic statuses are being known and being justified. A meta-epistemic defeater is, on the other hand, one that only downgrades the meta-epistemic status of a belief. Examples of secondorder epistemic statuses are being objectively justified and being objectively known. Carter characterizes two types of meta-epistemic defeaters - error-theoretic and relativist ones - and shows that they raise interesting puzzles when we attempt to explain how meta-epistemic defeaters themselves can be defeated.

Contributions of type (2) 
Albert Casullo's “Pollock and Sturgeon on Defeaters" contends that Sturgeon (2014)'s account of undercutting defeaters (summarized before) is all at once too strong and too weak. To settle these difficulties, Casullo suggests it should be emended in the following way: $S$ 's justified belief that a source $S R$ is untrustworthy regarding to whether or not $P$ is true undercuts $S$ 's belief that $P$ just in case $S$ has some reason to believe that $P$ is based on $S R$. Casullo hence criticizes Sturgeon's claim that undercutting and rebutting defeaters work in essentially different ways. According to Casullo, this claim can only be vindicated if one pairs the strongly internalist account of undercutting defeaters, which Sturgeon is committed to, with an externalist account of rebutting defeaters. For Casullo this combination of views is however hard to motivate, and so is Sturgeon's conclusion about the different working of rebutting and undercutting defeaters.

Matthias Steup's “Destructive defeat and justificational force: the dialectic of dogmatism, conservatism, and meta-evidentialism" addresses the question whether a subject $S$ 's perceptual defeater can destroy a perceptual experience of $S$ as a source of justification for believing $P$, rather than merely destroying $S$ 's all thing considered justification for $P$. Steup scrutinizes the negative answer given to this question by dogmatism, and the positive answers given by (what he calls) perceptual conservatism and meta-evidentialism. He concludes that the positive answer based on meta-evidentialism is the most plausible.

Nikolaj Pedersen's “Non-rational action in the face of disagreement: an argument against (strong) non-conformism" offers an original case against a brand on non-conformism, which he calls strong non-conformism, in the epistemology of disagreement. Pedersen characterizes strong non-conformism as the view that disagreement with a perceived peer generally or typically doesn't act as a defeater of the justification of the peers. Pedersen's argument is premised on the principle that $S$ acts rationally, when performing a goal-oriented action, only if $S$ has adequate epistemic justification pertaining to the success conditions of the relevant action. The argument concludes that strong non-conformism is flawed because in cases in which this principle is intuitively violated, it gives the incorrect verdict that it is not violated. 


\section{Contributions of type (3)}

Berit Brogaard's "In defense of hearing meanings" argues in favour of the view of language comprehension according to which fluent speakers have a non-inferential capability of experiencing the contents of the uttered sentences. According to this view, in the absence of defeaters these experiences give the speakers justification for their beliefs about the content of what is said. Brogaard's defence hinges on, among other things, investigating the dependence of the justificatory features of experience on the notion of a defeater.

Kathrin Glüer-Pagin's “Defeating Looks” is devoted to further articulating Glüer-Pagin (2009)'s doxastic account of experience, according to which perceptual experiences are beliefs with contents with a sui generis phenomenal semantics and with form "it looks as if $P$ ". If to have an experience as of $P$ is to believe that it looks as if $P$, the formation of perceptual beliefs can be modeled as the transition from the belief that it looks as if $P$ to the belief that $P$. In this way, the defeasibility of perceptual justification is vindicated, for the inference from "it looks as if $P$ " to " $P$ " can be defeated. Glüer-Pagin's contribution looks closer at the inferential relation between the contents of $S$ 's experiences and of $S$ 's perceptual beliefs, and at the conditions that must be satisfied for the latter beliefs to be defeated. It argues for a position according to which the reasons provided by experiences are good unless defeated.

Peter Graham's “Formulating reductionism about testimonial warrant and the challenge from childhood testimony" aims to defend the so-called child objection to reductionism about testimonial warrant from Lackey (2005)'s counter-argument and independent criticism depending on evidence from psychology. Reductionism about testimonial warrant says that testimonial warrant is always reducible to non-testimonial (e.g. perceptual and mnemonic) warrant that the hearer possesses. The child objection replies that since small children do have testimonial warrant but cannot have the required non-testimonial warrant, reductionism is false. To defend the child objection Graham sharpens it by re-formulating the argument in terms of positive higher-order 
reasons and negative higher-order reasons (i.e. undermining defeaters) to respectively trust or distrust speakers that small children cannot possess.

Kevin McCain's “Explanationist aid for phenomenal conservatism” examines the problem arising from conceiving of phenomenal conservatism as a theory of all justification, capable of explaining non-inferential justification, inferential justification and defeaters. McCain argues that although phenomenal conservatism, as standardly formulated, is unable to account for certain types of defeaters (e.g. defeaters that are not based on seemings and higher-order defeaters) and for inferential justification in general, it will nevertheless acquire the capability of doing both things once combined with a form of explanationism.

Matthew McGrath's "Defeating pragmatic encroachment?" returns to a central argument given first in Fantl and McGrath (2009) in support of the controversial thesis of pragmatic encroachment (PE) - the thesis that whether $S$ knows that $P$ can vary with the stakes, holding fixed $S$ 's warrant for $P$. The argument moves from the intuitively plausible premise that if $S$ knows that $P$, then $P$ is warranted enough for $S$ to have it as a reason for her actions. In this contribution, McGrath explores the possibility to accept this premise while blocking the argument for PE by adducing various types of defeaters of $S$ 's reasons or defeaters that make the actions recommended by $S$ 's reasons in a sense vicious. McGrath concludes that neither proposal can defeat the argument for PE.

Duncan Pritchard's "Anti-luck virtue epistemology and epistemic defeat" argues in favour of what he calls anti-luck virtue epistemology by showing that it is doesn't merely offer an adequate account of epistemic defeat but it is also able to provide an illuminating and multi-layered diagnosis of this phenomenon. For instance, anti-luck virtue epistemology casts light on important features of what Pritchard calls normative defeaters (i.e. defeaters of which one is unaware but which one epistemically ought to be aware of) and actual defeaters (i.e. defeaters which one is aware of). 
Audi, R. (2002). The Sources of Knowledge. In P. Moser (ed.), The Oxford Handbook of Epistemology (pp. 71-94). Oxford: OUP.

Bergman, M. (2006). Justification without Awareness. Oxford: OUP.

Bonjour, L. (1980). Externalist Theories of Empirical Knowledge. In P. A. French, T. E. Uehling, \& H. K. Wettstein (eds.), Midwest Studies in Philosophy, Vol. 5 (pp. 53-73). Minneapolis: University of Minnesota Press.

Carey B. (2011). Possible Disagreements and Defeat. Philosophical Studies, 155(3), 371-381.

Carter, A., \& Navarro, J. (2017). The defeasibility of knowledge-how. Forthcoming in Philosophy and Phenomenological Research.

Casullo, A. (2003). A Priori Justification. Oxford: OUP.

Chandler, J. (2013). Defeat Reconsidered. Analysis, 73(1), 49-51.

Chisholm, R. (1964). The Ethics of Requirement. American Philosophical Quarterly, 1(2), 147153.

Christensen, D. (2007a). Epistemic Self-Respect. Proceedings of the Aristotelian Society, 107, 319337.

Christensen, D. (2007b). Does Murphy's Law Apply in Epistemology? Self-Doubt and Rational Ideals. In T. S. Gendler \& J. Hawthorne (eds.), Oxford Studies in Epistemology Vol. 2 (pp. 331). Oxford: OUP.

Christensen, D. (2007c). Epistemology of Disagreement: the Good News. Philosophical Review, $116(2), 187-217$

Christensen, D. (2009). Disagreement as Evidence: The Epistemology of Controversy. Philosophy Compass, 4(5), 1-12.

Christensen, D. (2010). Higher-Order Evidence. Philosophy and Phenomenological Research, $81(1), 185-215$.

Coates, A. (2012). Rational epistemic akrasia. American Philosophical Quarterly, 45(2), 113-124. 
Cohen, S. (2013). A defense of the (almost) equal weight view. In D. Christensen \& J. Lackey (eds.) The Epistemology of Disagreement: New essays (pp. 98-117). Oxford: OUP.

Comesana, J. (2012). Conciliation and Peer-Demotion in the Epistemology of Disagreement. American Philosophical Quarterly, 49(3), 237-252.

De Almeida C., \& Fett, J.R. (2015). Defeasibility and Gettierization: A Reminder. Australasian Journal of Philosophy, 94(1), 152-169.

Dennis, P. (2014). Criteria for Indefeasible Knowledge: John McDowell and 'Epistemological Disjunctivism'. Synthese, 191(17), 4099-4113.

Fantl, J., \& McGrath, M. (2009). Knowledge in an uncertain world. Oxford: OUP.

Feldman, R. (2005). Respecting the Evidence. Philosophical Perspectives, 19, Epistemology, 95119.

Feldman, R. (2009). Evidentialism, Higher-order Evidence, and Disagreement. Episteme, 6(3), 294312.

Glüer-Pagin, K. (2009). In defence of a doxastic account of experience. Mind and Language, 24, 297-373.

Grundmann, T. (2009). Reliabilism and the Problem of Defeaters. Grazer Philosophische Studien, 79(1), 65-76.

Grundmann, T. (2011). Defeasibility Theories. In S. Bernecker \& D. Pritchard (eds.), Routledge Companion to Epistemology (156-256). London: Routledge.

Horowitz, S. (2014) Epistemic Akrasia. Nous, 48(4), 718-744.

Janvid, M. (2008). The Experiential Defeasibility and Overdetermination of A Priori Justification. Journal of Philosophical Research, 33, 121-128.

Janvid, M. (2012). Toward a Default and Challenge Model of A Priori Warrant. Journal of Philosophical Research, 37, 135-154.

Johnson, D. M. (2011). Proper Function and Defeating Experiences. Synthese, 182(3), 433-447. 
Kelly, T. (2005). The Epistemic Significance of Disagreement. In J. Hawthorne \& T. S. Gendler (eds.), Oxford Studies in Epistemology Vol. 1 (167-196) Oxford: OUP.

Kelly, T. (2010). Peer Disagreement and Higher-Order Evidence. In R. Feldman \& T. A. Warfield (eds.), Disagreement (pp. 111-174). Oxford: OUP.

Klein, P. (1976). Knowledge, Causality, and Defeasibility. The Journal of Philosophy, 73, 792-812.

Lackey, J. (2005). Testimony and the infant/child objection. Philosophical Studies, 126(2), 163190.

Lackey, J. (2008). Learning from Words. Testimony as a Source of Knowledge. Oxford: OUP. Lasonen-Aarnio, M. (2014). Higher-order evidence and the limits of defeat. Philosophy and Phenomenological Research, 88(2), 314-345.

Lehrer, K., \& Paxson, T. (1969). Knowledge: Undefeated Justified True Belief. The Journal of Philosophy, 66(8), 225-237.

Matheson J. (2009). Conciliatory Views of Disagreement, and Higher-order evidence. Episteme, $6(3), 269-279$.

McDowell, J. (2008). Avoiding the myth of the given. In J. Lindgaard \& J. McDowell (eds.), Experience, norm, and nature (pp. 1-14). Oxford: Wiley-Blackwell.

McDowell, J. (2010). Tyler Burge on disjunctivism. Philosophical Explorations, 13(3), 243-255.

McDowell, J. (2011). Perception as a capacity for knowledge. Milwaukee, WI: Marquette University Press.

Melis, G. (2014). Understanding Undermining Defeat. Philosophical Studies, 170(3), 433-442.

Moretti, L. (2015). Phenomenal Conservatism. Analysis, 75(2), 296-309.

Moretti, L., \& T. Piazza (2013). Transmission of justification and warrant. In E. N. Zalta (ed.), The Stanford Encyclopedia of Philosophy. https://plato.stanford.edu/entries/transmissionjustification-warrant/

Pollock, J. L. (1974). Knowledge and justification. Princeton: Princeton University Press.

Pollock, J. L. (1987). Defeasible Reasoning. Cognitive Science, 11(4), 481-518. 
Pritchard, D. (2012) Epistemological Disjunctivism. Oxford: OUP.

Pryor, J. (2000). The Skeptic and the Dogmatist. Nous, 34, 517-549.

Pryor, J. (2013). Problems for credulism. In C. Tucker (ed.), Seemings and justification: New essays on dogmatism and phenomenal conservatism (pp. 89-132).NY: OUP

Rotondo A. (2013). Undermining, Circularity, and Disagreement. Synthese, 190(3), 563-584.

Schechter, J. (2011). Rational Self-Doubt and the Failure of Closure. Philosophical Studies, 163(2), 429-452.

Silins, N. (2014). The Agony of Defeat? Philosophy and Phenomenological Research, 88(3), 505532.

Sturgeon, S. (2014). Pollock on defeasible reasons. Philosophical Studies, 169(1), 105-118.

Sudduth, M. (2017). Defeaters in Epistemology. In J. Fieser \& B. Dowden (eds.), Internet Encyclopedia of Philosophy. http://www.iep.utm.edu/ep-defea/

Swain, M. (1974). Epistemic Defeasibility. American Philosophical Quarterly, 11 (1), 12-25.

Thune, M. (2010). 'Partial defeaters' and the epistemology of disagreement. Philosophical Quarterly, 60(239), 355-372.

Thurow, J. (2006). Experientially Defeasible A Priori Justification. Philosophical Quarterly 56, 596-602.

Titelbaum, M. (2015). Rationality's fixed point (or: in defence of right reason). In Gendler S. T. \& J. Hawthorne (eds), Oxford Studies in Epistemology Vol. 5 (pp. 253-294). Oxford: OUP.

Warenski, L. (2009). Naturalism, Fallibilism, and the A Priori. Philosophical Studies, 142(3), 403426.

Weatherson, B. (2013). Disagreements, philosophical, and otherwise. In D. Christensen \& J. Lackey (eds.) The Epistemology of Disagreement: New essays (pp. 54-73) Oxford: OUP.

Wedgwood, R. (2011). Justified inference. Synthese, 189(2), 1-23.

Weisberg, J. (2009). Commutativity or Holism: A Dilemma for Conditionalizers. British Journal for the Philosophy of Science, 60(4), 793-812. 
Weisberg, J. (2015). Updating, Undermining, and Independence. British Journal for the Philosophy of Science, 66(1), 121-159.

Williamson, T. (2007). The Philosophy of Philosophy. Oxford: OUP

Wright, C. (2004). Warrant for Nothing (and Foundations for Free?). Proceedings of the Aristotelian Society, Supplementary Volume 78, 167-212. 